\title{
Physical Modeling Technological Regimes of Production Deformed Semi-Finished Products from Experimental Aluminium Alloys Alloyed by Scandium
}

\author{
Vladimir Baranov ${ }^{1}$, Sergey Sidelnikov ${ }^{1, a^{*}}$, Evgeniy Zenkin ${ }^{2}$ \\ and Olga Yakivyuk ${ }^{1}$ \\ ${ }^{1}$ Siberian Federal University, 660025, Krasnoyarsk, Krasnoyarskiy Rabochiy ave., 95, Russia \\ ${ }^{2}$ «RUSAL Bratsk Aluminum Smelter» JSC, 665710, Bratsk, BrAS, 1, Russia \\ asbs270359@yandex.ru
}

Keywords: aluminum alloys of the Al-Mg system, scandium, rolling, extruding, sheet semi-finished products, welding wire, mechanical properties, corrosion resistance.

\begin{abstract}
The combination of weldability, corrosion resistance and sufficient strength make it possible to use deformed semi-finished products from the Al-Mg system alloys for sheathing ships' hulls, in car, aircraft and rocket construction, as well as in other areas of industry. To increase the strength characteristics, it is promising to alloy them with small additives of metals such as titanium, zirconium, scandium, and others. In this paper, studies were carried out to obtain deformed semi-finished products (strips, rods and wires) from aluminum alloys in which the scandium content varied from 0.1 to $0.25 \%$. For this purpose, various metal treatment conditions simulated in the laboratory of School of Non-Ferrous Metals and Material Science in Siberian federal university. For the preparation of sheet semi-finished products regimes of hot and cold rolling of a cast billet simulated from a thickness of $40 \mathrm{~mm}$ to a thickness of $3 \mathrm{~mm}$. For the preparation of sheet semi-finished products, the modes of hot and cold rolling of the cast billet from a thickness of $40 \mathrm{~mm}$ to a thickness of 1-3 $\mathrm{mm}$ have been modeled. To produce a welding wire with a size of $2 \times 2 \mathrm{~mm}$, a combined casting and rolling-extruding (CCRE) process was simulated to produce a $9 \mathrm{~mm}$ billet and its further rolling in square gauges. Rods with a diameter of $9 \mathrm{~mm}$ were produced on a combined processing unit, and wire on a rolling mill with a roll diameter of $130 \mathrm{~mm}$. In accordance with the research program, the mechanical properties of hot-deformed, colddeformed and annealed sheet semi-finished products were measured. Then the semi-finished products were welded together with the obtained wire and the quality and properties of the welded joint and their corrosion resistance were evaluated. Research results are currently used to develop industrial technologies for the production of sheets and plates from experimental alloys of the AlMg system doped with scandium.
\end{abstract}

\section{Introduction}

For the shelling of ships' hulls, in car, aircraft and rocket construction, as well as in other areas of industry, sheet metal (sheets and strips) made of corrosion-resistant alloys of the Al-Mg system are widely used. The alloying of such alloys with small additions of scandium provides an increase in the strength of these alloys as a result of dispersion hardening and structural hardening. In the case of nonequilibrium crystallization of magnalic scandium in the range $0.4-0.5 \%$, it mainly dissolves in aluminum, forming a supersaturated solid solution [1]. During technological heating of ingots and semi-finished products, the supersaturated solid solution decays with the formation of coherent particles of the strengthening phase $\mathrm{Al}_{3} \mathrm{Sc}$. An additional effect of hardening is associated with the introduction into the alloy of small additions of zirconium, which is part of the secondary phase precipitates $\mathrm{Al}_{3}(\mathrm{Sc}, \mathrm{Zr})$, and slows the coagulation process of the decomposition products of the solid solution [2].

In recent years, many scientific publications, including foreign ones, have been devoted to research in the field of creating such alloys and studying the properties of products made from them using thermal deformation technologies [3-17]. The relevance of these studies is also emphasized by 
the fact that research work was carried out with the financial support of the Government of the Russian Federation. The article was prepared using the results of the work carried out during the project 03.G25.31.0265 "Development of economically alloyed high-strength Al-Sc alloys for use in road transport and navigation" within the framework of the Program for the implementation of complex projects for the creation of high-tech production, approved by the Government of the Russian Federation on April 92010 №218.

The aim of the work was to obtain samples of sheet metal and welding wire from experimental alloys of the Al-Mg system doped with scandium, as well as to study their mechanical and operational properties. Wire, which was used for welding sheet semi-finished products was manufactured using the technology of combined casting and rolling-extruding [18], profiled rolling and subsequent drawing.

\section{The Results of Experimental Studies for the Development of Technological Regimes for the Production of Sheet Metal}

Under experimental casting conditions, flat ingots with dimensions $560 \times 1360 \times 4520 \mathrm{~mm}$ were made from an experimental aluminum alloy in which the magnesium content was $5 \%$, scandium $0.12 \%$, zirconium $0.12 \%$ and other elements with a total content of $1.1 \%$.

In the conditions of pilot-industrial casting flat ingots with sizes $560 \times 1360 \times 4520 \mathrm{~mm}$ from experimental aluminium alloys have been made. From the ingots were cut platen, which is manufactured from the blank of rectangular shape with milled edges for rolling (Fig. 1, $a$ ).

Dimensions of workpieces in the simulation of technological rolling regimes were chosen on a scale of 1:10 to the dimensions of industrial ingots.

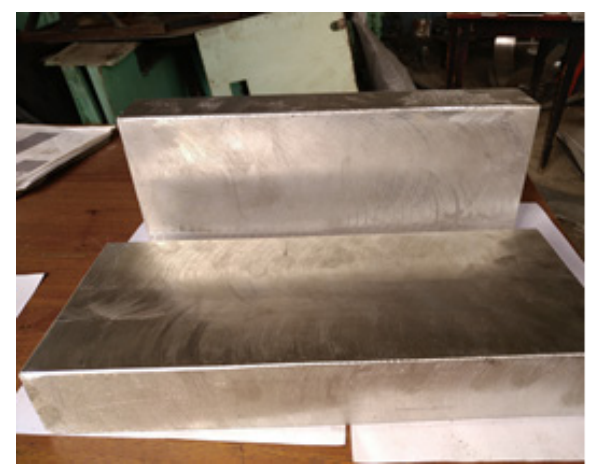

$a$

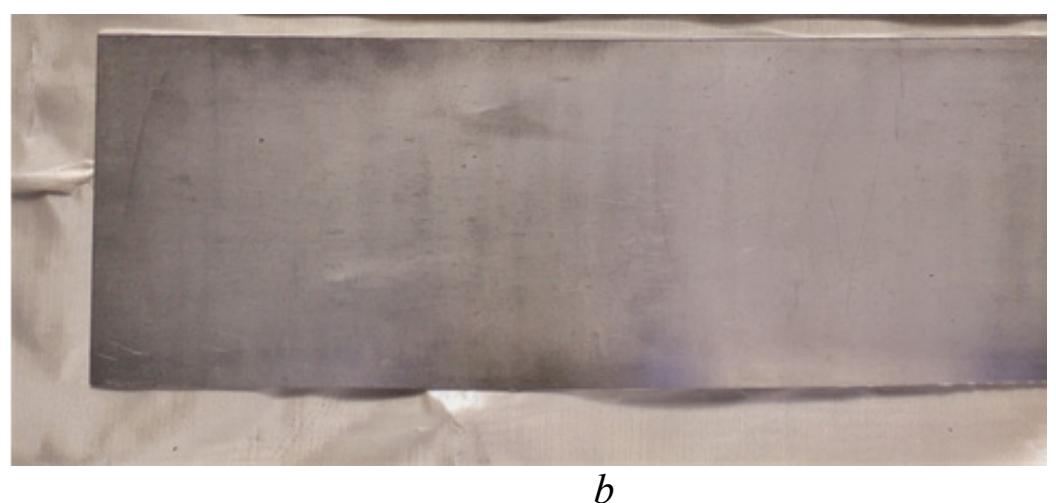

$b$

Fig. 1. Blanks for rolling $(a)$ and the rolled strip $(b)$ from the experimental alloy

The blanks were subjected to homogenization annealing according to the following regime (Fig. 2): heating with oven at speed $1.16^{\circ} \mathrm{C}$ per minute to temperature $350^{\circ} \mathrm{C}$; holding at this temperature for 11 hours; reheating to temperature $425^{\circ} \mathrm{C}$ with speed $1.25^{\circ} \mathrm{C}$ per minute; holding at this temperature for 8 hours; air cooling.

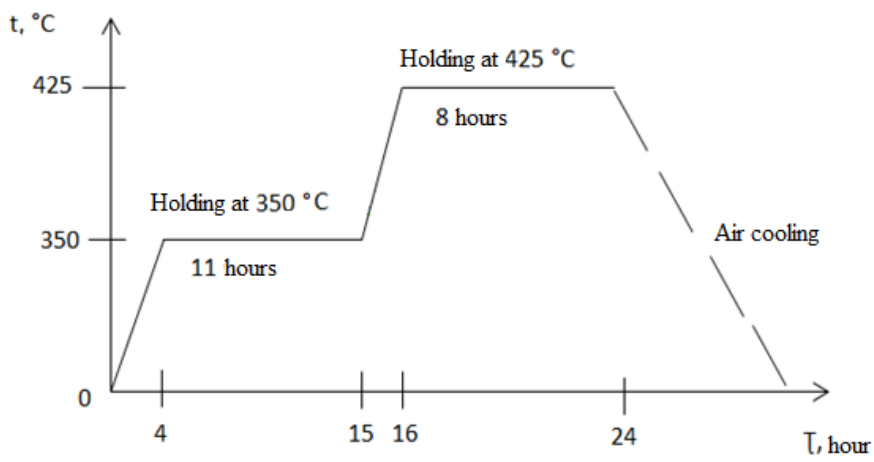

Fig. 2. Diagram for heat treatment of flat ingots from experimental alloys 
Each billet was heated to a temperature $450^{\circ} \mathrm{C}$ and rolled on a two-roll mill with a roll diameter of 330 for various processing options, varying the reduction values. The total degree of deformation during hot rolling was $75-81 \%$, and during cold rolling degree of deformation was $70-90 \%$. The single draw ratio per pass varied from 1.04 to 1.2 . The obtained bands 1 and $3 \mathrm{~mm}$ thick were annealed at a temperature $350^{\circ} \mathrm{C}$ and holding time 3 hours.

For rolled strips of samples was determined ultimate tensile strength $R_{m}$, yield strength of metal $R_{P}$ and elongation to failure $A$.

The study of the microstructure of the metal was carried out using a light microscope Axio Observer A1.m and a scanning electron microscope EVO 50 of firm Carl Zeiss at enlargement of the image 50-500 times.

Studies mechanical properties of metal after rolling and annealing were carried out by tensile testing machine LFM400 with effort $400 \mathrm{kN}$. From the obtained strips, flat samples were cut with a working length of $50 \mathrm{~mm}$ and a width of $20 \mathrm{~mm}$, which were subjected to tensile tests at room temperature and a deformation rate of $20 \mathrm{~mm} / \mathrm{min}$.

In determining the strength and plastic properties of the samples, the change in the length of the working part of the sample was recorded each time, and also the value of the tensile force $P$ corresponding to this change.

Then, ultimate tensile strength $R_{m}$ and elongation to failure $A$ were determined from the known formulas:

$$
R_{m}=\frac{P}{S_{0}} ; \quad A=\frac{L_{u}-L_{0}}{L_{0}} \cdot 100 \%
$$

where $P$ - The maximum tensile force over the whole area of plastic deformation of the sample, preceding the moment of neck formation; $S_{0}$ - initial cross-sectional area; $L_{0}$ - initial length of the working section of the sample; $L_{u}$ - length of the working section of the sample after the test.

The results of testing the mechanical properties of samples of different thicknesses in the deformed and annealed state for one of the experimental alloys are given in Table 1.

Table 1. Mechanical properties of sheet metal from experimental alloy

\begin{tabular}{|c|c|c|c|c|c|}
\hline $\begin{array}{c}\text { Number of } \\
\text { sample }\end{array}$ & Thickness, & \multirow{2}{*}{ State } & \multicolumn{3}{|c|}{ Mechanical properties } \\
\cline { 3 - 5 } & $\mathrm{mm}$ & Hot deformed & 369 & 266 & 15 \\
\hline 1 & 10 & Hot deformed & 372 & 280 & 15 \\
\hline 2 & 8 & Hot deformed & 387 & 312 & 12 \\
\hline 3 & 6 & Cold deformed & 453 & 429 & 5 \\
\hline 4 & 3 & Cold deformed & 554 & 467 & 3,9 \\
\hline 5 & 1 & Annealed & 390 & 277 & 14 \\
\hline 6 & 3 & Annealed & 425 & 282 & 12,8 \\
\hline 7 & 1 & &
\end{tabular}

Analysis of the mechanical properties of the obtained semi-finished products shows that the level of strength and plastic properties is high enough, while the tensile strength reaches for cold-deformed samples $453-554 \mathrm{MPa}$, yield strength of the metal is $429-467 \mathrm{MPa}$, and elongation is 3.9-5.0\%.

As general patterns of changes in mechanical properties, it can be noted that with an increase in the total degree of deformation, the tensile strength and the yield strength of the metal increase, and the relative elongation decreases, which corresponds to the general concepts of the theory of metal forming.

The use of annealing after cold rolling made it possible to obtain good plastic properties of the metal (the values of the relative elongation increase and reach 12.8-14\%) at sufficiently high yield stress (277-282 MPa).

This level of mechanical properties makes it possible to fabricate deformed semi-finished products in the form of sheet metal from the ingots of the experimental alloy with a sufficiently low content of scandium substituted with zirconium. 
The metallographic analysis of the obtained samples showed that the deformation changes the structural state of the metal, as a result of which the grains are stretched in the direction of deformation, forming a fibrous structure. Deformation leads to a distortion of the crystal structure of the metal, an increase in the density of dislocations and vacancies. During hot deformation, the fine structure changes, subgrains are formed, which provides weakening of alloys in comparison with cold deformation. An increase in the degree of deformation during cold rolling of semi-finished products leads to their hardening and reduction in ductility. Microstructure of deformed samples from the experimental alloy (Fig. 3) consists of elongated grains of $\alpha$-solid solution and inclusions of intermetallic compounds arranged in the form of lines along the grain boundaries. In the microstructure of the samples after hot rolling of the experimental alloy fairly large light-gray particles in the form of plates and crystals having a branched shape, 12-45 $\mu \mathrm{m}$ in size with a thickness of $10 \mathrm{~mm}$ and a size of $7-38 \mu \mathrm{m}$ with a thickness of $6 \mathrm{~mm}$ have been identified. The microstructure of the deformed articles also includes gray crystals in the form of polyhedral and dark-colored crystals in the form of extended crushed plates located along the direction of deformation and irregularly shaped dark crystals.

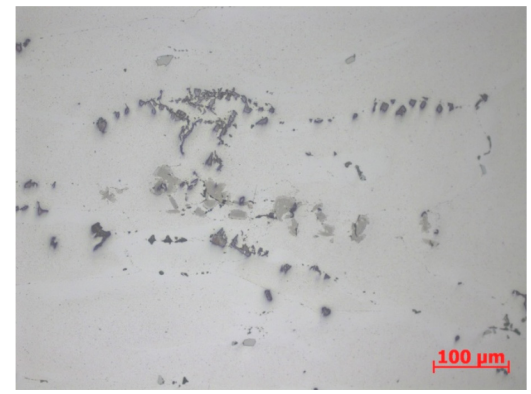

$a$

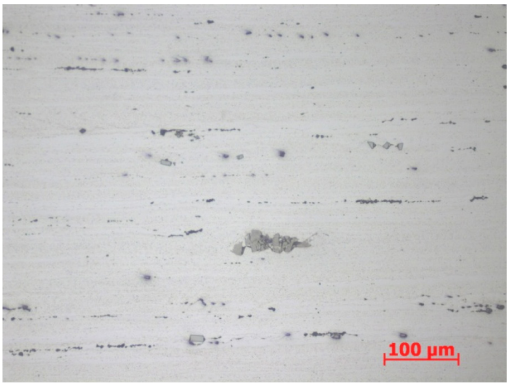

$b$

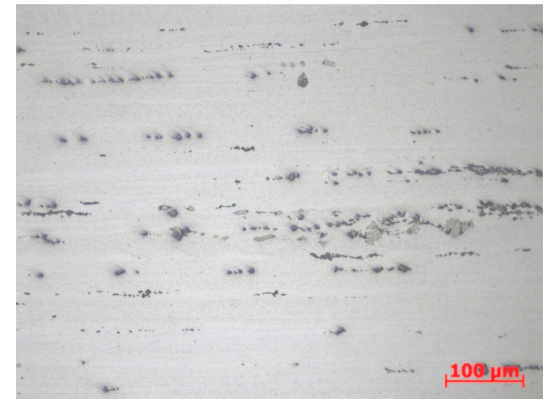

$c$

Fig. 3. Microstructure of semi-finished products from an experimental alloy: $a-$ samples $10 \mathrm{~mm}$ thick after hot rolling; $b$ - samples $3 \mathrm{~mm}$ thick after cold rolling; $c$ - samples $3 \mathrm{~mm}$ thick after cold rolling and annealing; $\times 200$

In the microstructure of the samples, after the hot rolling of the experimental alloy, fairly large light-gray particles in the form of plates and crystals having a branched shape, $12-45 \mu \mathrm{m}$ in size with a thickness of $10 \mathrm{~mm}$ and a size of 7-38 $\mu \mathrm{m}$ with a thickness of $6 \mathrm{~mm}$ were detected. The microstructure of the deformed articles also includes gray crystals in the form of polyhedral and dark-colored crystals in the form of extended crushed plates located along the direction of deformation and irregularly shaped dark crystals.

\section{The Results of Experimental Studies for the Development of Technological Regimes for the Production of Welding Wire}

The workpiece for a welding wire with a diameter of $9 \mathrm{~mm}$ was obtained from an experimental alloy of the Al-Mg system based on the alloy 01570 , in which the amount of magnesium was $5 \%$, scandium $0.25 \%$, zirconium $0.07 \%$, and other elements $0.83 \%$, by the method of combined casting and rolling-extruding [19,20], and the wire itself with a diameter of $3 \mathrm{~mm}$ was obtained by subsequent bar rolling and drawing.

The metal melt was prepared in an electric furnace, while in the ceramic crucible the alloy was heated to a temperature $780-790{ }^{\circ} \mathrm{C}$, held for 10 minutes and poured into rolls heated to $100{ }^{\circ} \mathrm{C}$. For forming the metal used unit of combined processing CRE-200 mounted on the basis of a rolling mill DUO-200 with a diameter of rolls of $200 \mathrm{~mm}$ [19]. The experimental procedure was as follows. The metal melt was poured into the box caliber of the rotating rolls, crystallized, reduced and extruded through the matrix hole pressed against the rolls by means of a hydraulic cylinder with a calibrated aperture $9 \mathrm{~mm}$ in diameter. Therefore, as a finished product, semi-finished products (rolled wire) of circular cross-section of the indicated size have been receipted. Force parameters of the process of deformation (force $P_{\text {roll }}$, acting on rolls, and force $P_{\text {matrix }}$, acting on the matrix) fixed 
with strain gauge load cells and instrumentation. As a result of measurements obtained $P_{\text {roll }}=$ $274,4 \mathrm{kN}$, and $P_{\text {matrix }}=186,2 \mathrm{kN}$.

Then, in the octagonal calibers, a square-section bar with cut corners was produced (Fig. 4) by cold rolling on a two-mill rolling unit model AMBIFILO VELOCE ROSEN 180+200 with roll diameter $130 \mathrm{~mm}$ of firm Mario Di Maio) with intermediate anneals at temperature $400{ }^{\circ} \mathrm{C}$.

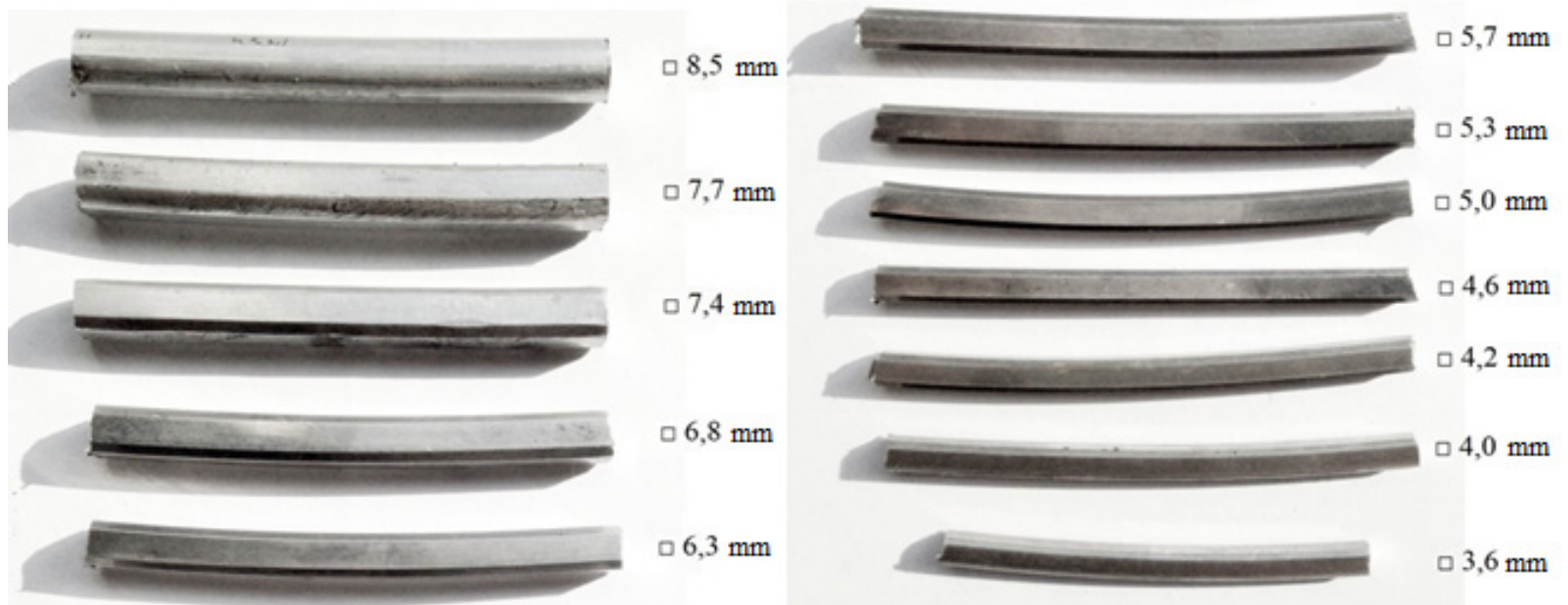

Fig. 4. Appearance of profiled rods after rolling

After this, the resulting rod with a side of $5 \mathrm{~mm}$ was drawn on a single-action chain drawing machine with a force of $50 \mathrm{kN}$ at a drawing speed of $0.17 \mathrm{~m} / \mathrm{s}$ and a round wire with a diameter of $3 \mathrm{~mm}$ obtained.

In the course of the process, samples were taken for mechanical tests, the results of which are shown in Table 2.

\section{The Results of Experimental Studies for the Development of Technological Regimes for the Production of Welded Deformed Semi-Finished Products}

The resulting flat samples were welded along (method 1) and across (way 2) direction of deformation (Fig. 5) by means of argon-arc welding of strips using the obtained welding wire. Welding was performed using TIG-AC technology using a welding machine TIG200P. Samples with welded joints were heat treated at a temperature of $350{ }^{\circ} \mathrm{C}$ within 3 hours.

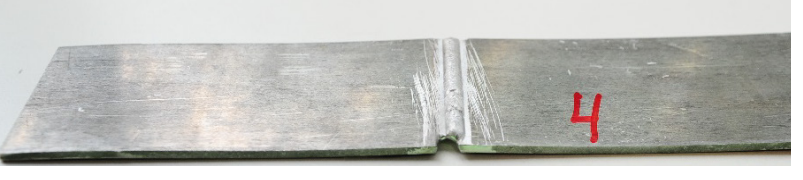

$a$

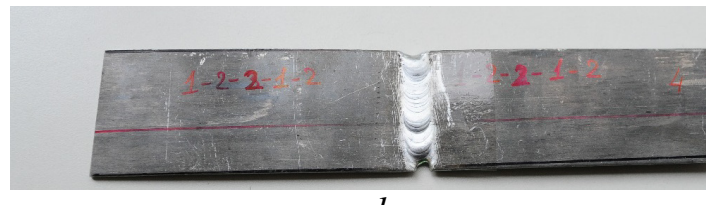

$b$

Fig. 5. Type of strip from the side of the weld $(a)$ and back side $(b)$

To assess the nature and degree of corrosion damage of the experimental alloys, accelerated tests for intergranular corrosion were carried out. Three types of samples were subjected to the tests: deformed, welded along and across the rolling. On all sides samples were washed with a solution containing: $58 \mathrm{~g} / 1 \mathrm{NaCl}$ and $10 \mathrm{ml} / 133 \%$ solution $\mathrm{H}_{2} \mathrm{O}_{2}$, temperature of the solution was $18-25{ }^{\circ} \mathrm{C}$, test duration $24 \mathrm{~h}$.

The samples were degreased with isopropyl alcohol before the intergranular corrosion test and dried with filter paper. Next, etching was carried out for 2 minutes in a solution containing $50 \mathrm{ml}$ of nitric acid (70\%), $5 \mathrm{ml}$ of hydrofluoric acid (48\%) and $945 \mathrm{ml}$ of water, at the temperature of the solution $95 \pm 3{ }^{\circ} \mathrm{C}$; then the samples were washed in cold water and clarified in $25-30 \%$ nitric acid solution, then washed again and dried with filter paper. After the end of the test, the samples were washed under running water and dried in an oven at a temperature of $100 \pm 5^{\circ} \mathrm{C}$ during 5 minutes.

The metallographic method on the prepared sections was used to determine the nature of corrosion on samples from the investigated alloys, determine the mechanical properties, the 
maximum depth and the distribution of corrosion along the edge of the section. Tests for intercrystalline corrosion of samples of experimental alloys showed high resistance to this type of corrosion, since single sections of intercrystalline corrosion with a length of 4-29 $\mathrm{m}$ and depth of 10-28 m were detected.

This was followed by a tensile test by the method described above and determined mechanical properties of the samples in the weld zone. The results of the studies are given in Table 3, while the strength of the welded joint is $0.75-0.85$ of the strength of the base metal. Metallographic studies have shown that the welded joint of the samples contains zones (Fig. 6), which differ in the shape and size of the grain.

Table 3. Mechanical properties of welded samples from experimental alloys

\begin{tabular}{|c|c|c|c|c|}
\hline \multirow{2}{*}{$\begin{array}{c}\text { Sample } \\
\text { number }\end{array}$} & $\begin{array}{c}\text { Method of welding } \\
\text { samples }\end{array}$ & \multicolumn{3}{|c|}{$\begin{array}{c}\text { Mechanical properties of samples } \\
\text { after welding and annealing }\end{array}$} \\
\cline { 3 - 5 } & 1 & $R_{m}, \mathrm{MPa}$ & $R_{P}, \mathrm{MPa}$ & $A, \%$ \\
\hline 1. & 2 & 362 & 246 & 6 \\
\hline 2. & 1 & 353 & 293 & 3.3 \\
\hline 3. & 2 & 361 & 250 & 2.6 \\
\hline 4. & 1 & 334 & 245 & 5.7 \\
\hline 5. & 2 & 351 & 242 & 3.3 \\
\hline 6. & 1 & 333 & 240 & 5.8 \\
\hline 7. & 2 & 344 & 250 & 3.1 \\
\hline 8. & 339 & 246 & \\
\hline
\end{tabular}

Table 2. Cold routing, drawing and mechanical properties of the welding wire

\begin{tabular}{|c|c|c|c|c|c|c|c|c|c|c|c|}
\hline 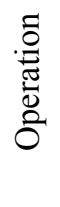 & $\begin{array}{c}\text { Number } \\
\text { of } \\
\text { caliber }\end{array}$ & $\begin{array}{l}\text { Size } \\
\text { of } \\
\text { side, } \\
\mathrm{mm}\end{array}$ & $\begin{array}{c}\text { Cross- } \\
\text { sectional } \\
\text { area } S \text {, } \\
\mathrm{mm}^{2}\end{array}$ & $\begin{array}{c}\text { Compre- } \\
\text { ssion, } \\
\mathrm{mm}\end{array}$ & $\begin{array}{l}\text { Single } \\
\text { draw } \\
\text { ratio } \\
\lambda_{\text {single }}\end{array}$ & $\begin{array}{l}\text { Total } \\
\text { draw } \\
\text { ratio } \\
\lambda_{\text {total }}\end{array}$ & $\begin{array}{c}\text { Single } \\
\text { degree } \\
\text { of } \\
\text { deforma- } \\
\text { tion, } \%\end{array}$ & $\begin{array}{c}\text { Total } \\
\text { degree } \\
\text { of } \\
\text { deforma- } \\
\text { tion, } \%\end{array}$ & $\begin{array}{l}\text { Ultimate } \\
\text { tensile } \\
\text { strength } \\
R_{m}, \mathrm{MPa}\end{array}$ & $\begin{array}{c}\text { Yield } \\
\text { strength } \\
P_{P}, \text { MPa }\end{array}$ & $\begin{array}{c}\text { Elonga- } \\
\text { tion to } \\
\text { failure } \\
A, \%\end{array}$ \\
\hline \multirow{13}{*}{ 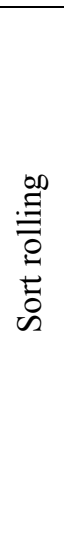 } & & $\varnothing 9,0$ & 63,6 & & & & & & 290,8 & 217,2 & 18,0 \\
\hline & 1 & 8,5 & 70,7 & 0,5 & 0,90 & 0,90 & & & & & \\
\hline & 2 & 7,7 & 58,9 & 0,8 & 1,20 & 1,08 & 16,7 & 16,7 & 326,1 & 296,6 & 8,63 \\
\hline & \multicolumn{8}{|c|}{ Annealing $400^{\circ} \mathrm{C}, 3$ hours } & 358,0 & 290,0 & 20,4 \\
\hline & 3 & 7,4 & 54,3 & 0,3 & 1,08 & 1,08 & 7,7 & 7,7 & & & \\
\hline & 4 & 6,8 & 45,3 & 0,6 & 1,20 & 1,30 & 16,7 & 23,1 & 423,6 & 391,2 & 7,1 \\
\hline & \multicolumn{8}{|c|}{ Annealing $400^{\circ} \mathrm{C}, 3$ hours } & 381,3 & 297,1 & 14,3 \\
\hline & 5 & 6,3 & 39,4 & 0,5 & 1,15 & 1,15 & 12,9 & 12,9 & & & \\
\hline & 6 & 5,7 & 31,9 & 0,6 & 1,24 & 1,42 & 19,1 & 29,5 & 412,7 & 360,6 & 7,2 \\
\hline & \multicolumn{8}{|c|}{ Annealing $400^{\circ} \mathrm{C}, 3$ hours } & 367,6 & 276,7 & 14,8 \\
\hline & 7 & 5,3 & 27,9 & 0,4 & 1,14 & 1,14 & 12,5 & 12,5 & & & \\
\hline & 8 & 5,0 & 24,3 & 0,3 & 1,15 & 1,31 & 12,7 & 23,7 & 421,4 & 400,8 & 5,8 \\
\hline & \multicolumn{8}{|c|}{ Annealing $400^{\circ} \mathrm{C}, 3$ hours } & 388,6 & 302,3 & 10,0 \\
\hline \multirow{12}{*}{ 点 } & 9 & $\varnothing 5,9$ & 27,3 & & & & & & & & \\
\hline & 10 & 4,8 & 18,1 & 0,2 & & 1,34 & & 25,5 & 437,6 & 426,3 & 1 \\
\hline & \multicolumn{8}{|c|}{ Annealing $400^{\circ} \mathrm{C}, 3$ hours } & 389,5 & 281,3 & 10,0 \\
\hline & 11 & 4,5 & 15,9 & 0,3 & 1,14 & 1,14 & 12,2 & 12,2 & & & \\
\hline & 12 & 4,0 & 12,6 & 0,5 & 1,26 & 1,44 & 20,8 & 30,4 & 422,3 & 415,4 & 1,8 \\
\hline & \multicolumn{8}{|c|}{ Annealing $400^{\circ} \mathrm{C}, 3$ hours } & 448,5 & 301,6 & 11,7 \\
\hline & 13 & 3,75 & 11,0 & 0,25 & 1,15 & 1,15 & 12,7 & 12,7 & & & \\
\hline & 14 & 3,6 & 10,2 & 0,15 & 1,08 & 1,24 & 7,3 & 19,0 & 458,3 & 429,3 & 3,5 \\
\hline & \multicolumn{8}{|c|}{ Annealing $400^{\circ} \mathrm{C}, 3$ hours } & 358,0 & 240,8 & 13,8 \\
\hline & 15 & 3,3 & 8,5 & 0,3 & 1,20 & 1,20 & 16,7 & 16,7 & & & \\
\hline & 16 & 3,0 & 7,1 & 0,3 & 1,20 & 1,44 & 16,5 & 30,4 & 431,7 & 413,0 & 2,2 \\
\hline & \multicolumn{8}{|c|}{ Annealing $400^{\circ} \mathrm{C}, 3$ hours } & 339,5 & 214,3 & 17,5 \\
\hline
\end{tabular}




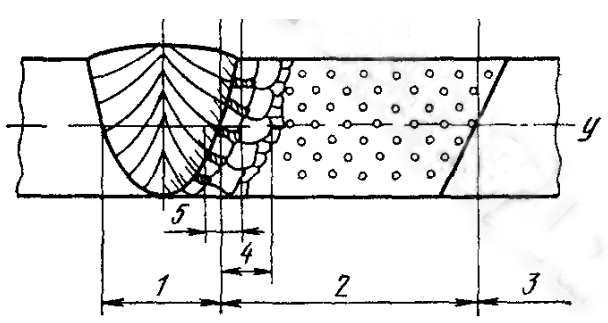

a

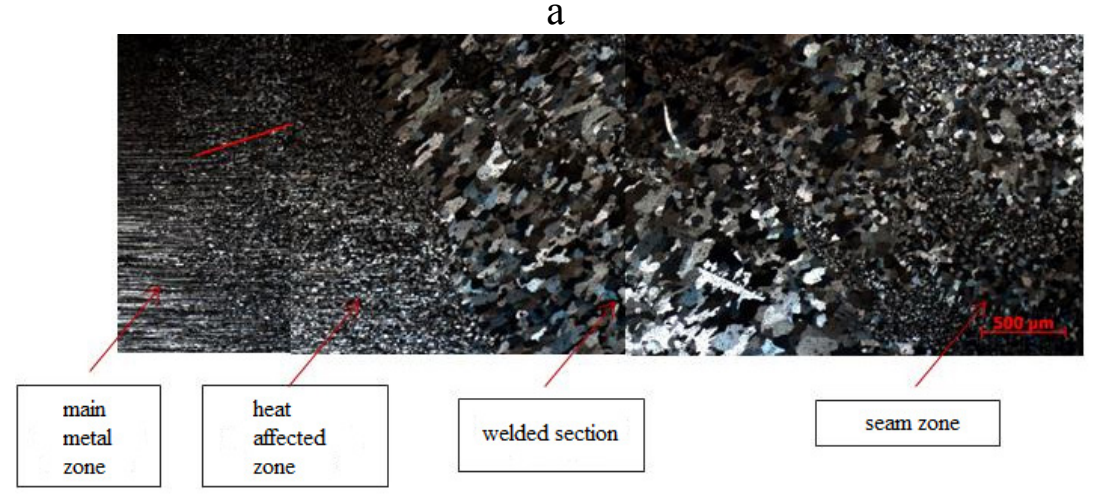

b

Fig. 6. Characteristic zones of welded joints: $a-$ scheme of welded zone; $b$ - zones of a welded joint on a microstructure; 1 - seam, 2 - heat affected zone, 3 - main metal, 4 - welded section of the heat affected zone, 5 - fusion zone

Studies of the microstructure of welded joints (Fig. 7) of $3 \mathrm{~mm}$ thick rolled products were carried out on a microscope Axio Observer A1.m, Carl Zeiss, including after deposition of an anisotropic oxide film in the regime of polarized light in a solution of boric acid (Fig. $7 \mathrm{a}, \mathrm{b}$ ).

The microstructure of the base metal and the heat affected zone is characterized, in comparison with the weld metal, by larger particles of excess phases located predominantly along the grain boundaries. The microstructure of the welded seam is represented by zones of segregation heterogeneity in the distribution of phases along the movement of the seam during crystallization, areas are identified, both depleted and enriched in the number of phases. Rapid crystallization of the welded joint ensures the formation of a dispersed structure and the small size of the excess phases. Defects in the zones of transition from the base metal and in the weld zone are observed in the form of micropores, the round shape of which assumes their gas-shrinkage origin.

The central zone of the seam in welded samples is represented by both large and small equiaxed crystals. In welded samples, a zone of thermal influence with a fine grain is determined, in which recrystallization processes have taken place, and the zone width is $1-2 \mu \mathrm{m}$. The grain size was evaluated on oxidized samples, it was established that the grain size in the thermal effect zone is approximately the same and is $13-15 \mu \mathrm{m}$, and the grain size of the coarse columnar crystals in the near-weld zone does not exceed $2.4 \mu \mathrm{m}$.

\section{Conclusion}

Thus, the conducted studies made it possible to obtain data on the level and patterns of the change in mechanical properties from the total degree of deformation of rolled products from a new alloy of the Al-Mg system doped with $0.12 \%$ scandium in a different state (hot, cold-deformed, annealed and welded). The wire for the production of welded samples was made by the method of combined casting and rolling-extruding, bar rolling and subsequent drawing of alloy Al-Mg system containing $0.25 \%$ scandium. Tests for intercrystalline corrosion of sheet metal samples showed high resistance to this type of corrosion, while the weld strength was $75-85 \%$ of the strength of the main metal. These data will be used in developing the technology of casting and processing of these alloys in industrial conditions. 


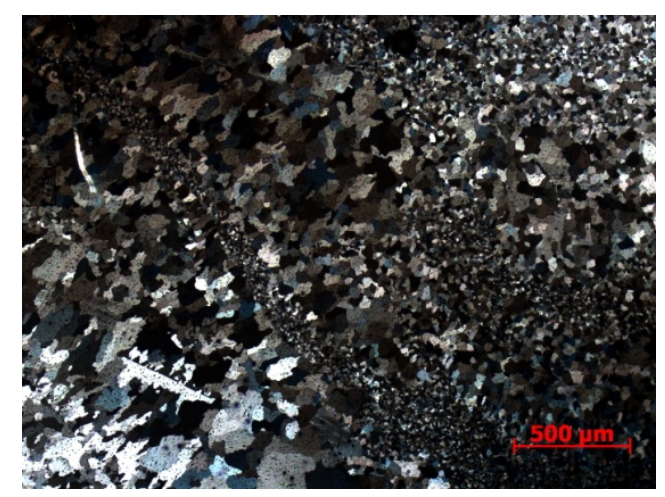

a, $\times 50$

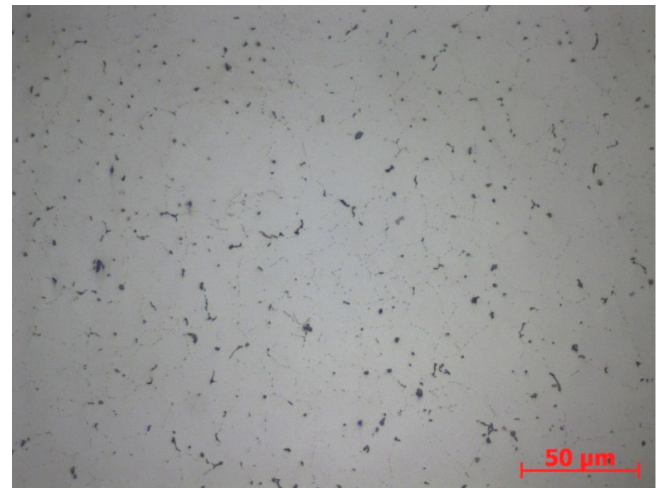

c, $\times 500$

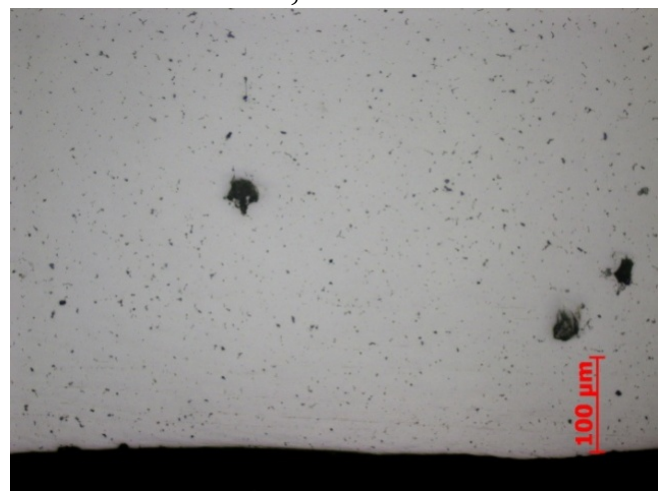

e, $\times 200$

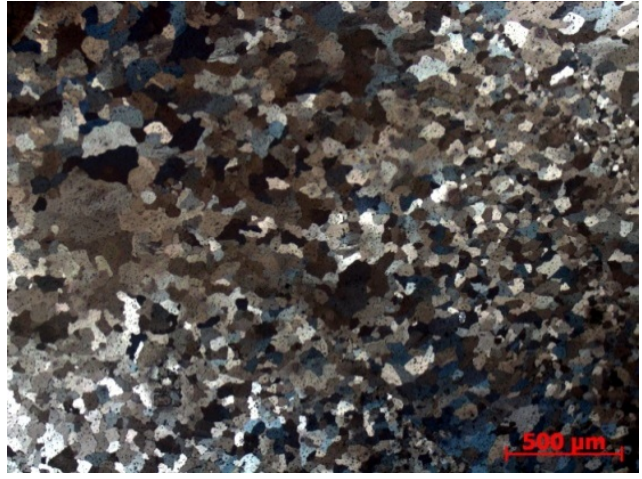

b, $\times 50$

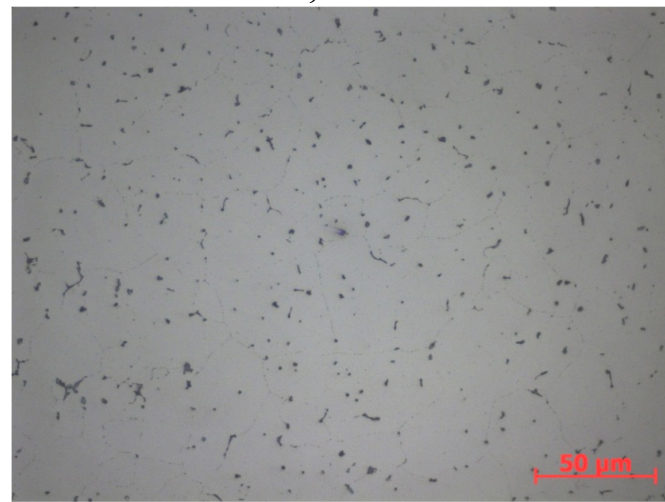

d, $\times 500$

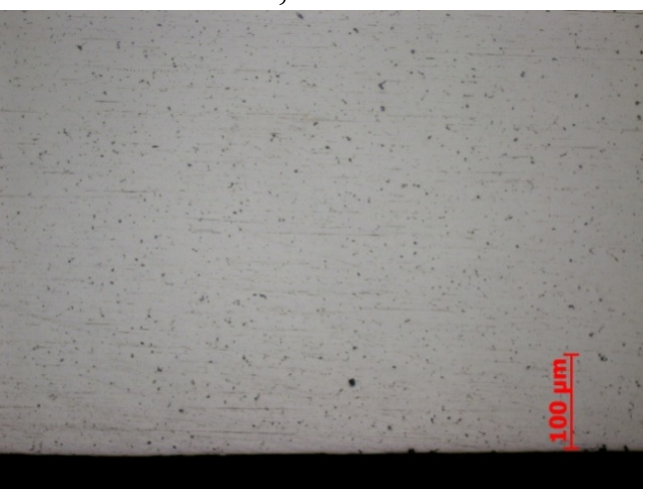

f, $\times 200$

Fig. 7. Microstructure of the welded seam along the rolling direction (a, c, e) and across the rolling direction $(b, d, f)$ : before intergranular corrosion $(a-d)$, after intergranular corrosion $(e, f)$

\section{References}

[1] Mondolfo L.F., Structure and properties of aluminum alloys, M.: Metallurgiya, 1979.

[2] Belov N.A., Phase composition of industrial and advanced aluminum alloys, Publ. House MISiS, 2010.

[3] S. Malopheyev, V. Kulitskiy, R. Kaibyshev, Deformation structures and strengthening mechanisms in an Al-Mg-Sc-Zr alloy, Journal of Alloys and Compounds. 698 (2017) 957-966.

[4] W. Kang, H.Y. Li, S.X. Zhao, Y. Han, C.L. Yang, G. Ma., Effects of homogenization treatments on the microstructure evolution, microhardness and electrical conductivity of dilute AlSc-Zr-Er alloys, Journal of Alloys and Compounds. 704 (2017) 683-692.

[5] R. Roumina, C.W. Sinclair., Recovery kinetics in the presence of precipitates: The softening response of an Al-Mg-Sc alloy, Acta Materialia. 58 (2010) 111-121. 
[6] Matthew E. Krug, Alexandra Werber, David C. Dunand, David N. Seidman., Core-shell nanoscale precipitates in Al-0.06 at.\% Sc microalloyed with Tb, Ho, Tm or Lu, Acta Materialia. 58 (2010) 134-145.

[7] Anthony De Luca, David C. Dunand, David N. Seidman, Mechanical properties and optimization of the aging of a dilute Al-Sc-Er-Zr-Si alloy with a high $\mathrm{Zr} / \mathrm{Sc}$ ratio, Acta Materialia. 119 (2016) 35-42.

[8] Y.W. Riddle, T.H. Sanders Jr., A Study of coarsening, recrystallization, and morphology of microstructure in Al-Sc-(Zr)-(Mg) alloys, Metallurgical and materials transactions A. 35A (2004) 341-350.

[9] H. Zhu, A.K. Dahle, A.K. Ghosh, Effect of Sc and Zn Additions on Microstructure and Hot Formability of Al-Mg Sheet Alloys, Metallurgical and materials transactions A. 40A (2009) 598608.

[10]C. Shi, L. Zhang, G. Wu, X. Zhang, A. Chen, J. Tao, Effects of Sc addition on the microstructure and mechanical properties of cast Al-3Li-1.5Cu-0.15Zr alloy, Materials Science \& Engineering. A680 (2017) 232-238.

[11]Pedro Henrique R. Pereiraa, Ying Chun Wang, Yi Huang, Terence G. Langdon, Influence of grain size on the flow properties of an Al-Mg-Sc alloy over seven orders of magnitude of strain rate, Materials Science \& Engineering. A685 (2017) 367-376.

[12] S. Mondol, T. Alamb, R. Banerjee, S. Kumar, K. Chattopadhyay, Development of a high temperature high strength $\mathrm{Al}$ alloy by addition of small amounts of $\mathrm{Sc}$ and $\mathrm{Mg}$ to 2219 alloy, Materials Science \& Engineering. A687 (2017) 221-231.

[13]M. Li, Q. Pan, Y. Shi, X. Sun, H. Xiang, High strain rate superplasticity in an Al-Mg-Sc-Zr alloy processed via simple rolling, Materials Science \& Engineering. A687 (2017) 298-305.

[14] Yu. Buranova, V. Kulitskiy, M. Peterlechner, A. Mogucheva, R. Kaibyshev, S.V. Divinski, G. Wilde, Al3(Sc, Zr) - based precipitates in AleMg alloy: Effect of severe deformation, Acta Materialia. 124 (2017) 210-224.

[15] Ibrokhimov S.Zh., Eshov B.B., Ganiev I.N., Ibrokhimov N.F., Vliyanie skandiya na fizikokhimicheskie svoistva splava AMg4 [Influence scandium on the physicochemical properties of the alloy AMg4], Izvestiya Samarskogo nauchnogo tsentra Rossiiskoi akademii nauk. 16(4) (2014) 256-260.

[16]Ibrokhimov S.Zh., Eshov B.B., Ganiev I.N., Okislenie tverdogo alyuminievo-magnievogo splava $\mathrm{AMg} 4$, legirovannogo skandiem [Oxidation of a hard aluminum-magnesium alloy AMg4, alloyed with scandium], Doklady akademii nauk respubliki Tadzhikistan. 56(6) (2013) 472-475.

[17]Filatov Yu.A., Razlichnye podkhody k realizatsii uprochnyayushchego effekta ot dobavki skandiya $\mathrm{v}$ deformiruemykh splavakh na osnove sistemy $\mathrm{Al}-\mathrm{Mg}-\mathrm{Sc}$ [Various approaches to realization of the strengthening effect resulted from scandium addition made to wrought $\mathrm{Al}-\mathrm{Mg}-\mathrm{Sc}$ system based alloys], VILS: Tekhnologiya legkikh splavov. 3 (2009) 42-45.

[18]Baranov V.N., Sidelnikov S.B., Bezrukikh A.I., Zenkin E.Y., Research of rolling regimes and mechanical properties of cold-rolled, annealed and welded semi-finished products from experimental alloys of $\mathrm{Al}-\mathrm{Mg}$ system, economically alloyed by scandium, Tsvetnye Metally. 9 (2017) 83-88.

[19]S.B. Sidelnikov, N.N. Dovzhenko, N.N. Zagirov, Combined and complex methods of machining non-ferrous metals and alloys, M.: MAKS PRESS, 2005.

[20]Nikolai Dovzhenko, Sergey Sidelnikov, Ivan Dovzhenko, Roman Galiev, New Technology of Combined Machining of Aluminium Alloys, Key Engineering Materials, 746 (2017) 29-35. 